\title{
¿Agarrar con gancho?: Aprehensión de técnicas corporales en la halterofilia'
}

\author{
Diana Marcela \\ Luisa María \\ Cardona Narváez² \\ Castaño Saldarriaga ${ }^{3}$ \\ dianamcn@hotmail.com \\ luimaicasa@gmail.com \\ Universidad Icesi \\ Universidad Icesi
}

Artículo corto de reflexión recibido 12/02/2019

y aceptado 02/03/2019

Cómo citar este artículo:

Cardona Narváez, D., \& Castaño Saldarriaga, L. (2019). ¿Agarrar con gancho?: aprehensión de técnicas corporales en la halterofilia. Trans-Pasando Fronteras, (13). doi: 10.18046/retf.i13.3417

\footnotetext{
1 Este texto es una reflexión grupal que ha tenido varias perspectivas de análisis que ha surgido por un interés mutuo frente al deporte y el cuerpo como objetos de investigación en las ciencias sociales.

2 Estudiante de noveno semestre de Sociología de la Universidad Icesi.

3 Estudiante de noveno semestre de Antropología de la Universidad Icesi.
} 


\section{Resumen}

Este texto pretende exponer la manera en que el espacio deportivo genera discursos técnicos sobre el cuerpo, su cuidado y su eficacia, reproduciendo constantemente determinadas prácticas que quedan a posteriori implantadas en el cuerpo de quien lo experimenta. Este planteamiento se desarrolla por medio de la halterofilia -también conocida como levantamiento de pesas-, como deporte ejemplo para dejar manifiesta la parte experiencial como deportista de una de las autoras del presente texto. Se añade también la apreciación conjunta de las autoras sobre cómo se extrapolan aquellos conocimientos físicos y emocionales que parecen sólo tener sentido en el deporte, a las diferentes esferas de la vida social, asegurando además la importancia del deporte, el cuerpo y la experiencia como objetos dignos de estudio en las ciencias sociales. Se sostiene entonces en este escrito que la adquisición de técnicas, gestos y la aprehensión de discursos sobre el cuerpo que se dan en el espacio deportivo, producen una re-interpretación del propio cuerpo y, por ende, una nueva forma de vivirlo.

Palabras clave: Halterofilia; Cuerpo; Deporte; Técnicas corporales; Impulso emocional. 
Tenía 11 años cuando un par de mujeres invitaron a varios estudiantes de mi colegio a ser parte de lo que sería un nuevo club de levantamiento de pesas. En sus cuerpos se evidenciaba el compromiso con el deporte y en su discurso la confianza en el éxito de este proyecto, pero esto último no era algo que a mí me interesara. Decidí ingresar sólo porque quería un cambio en mi cuerpo, estaba pasada de peso para mi edad, así que planeé hacer ejercicio y retirarme de inmediato cuando empezaran a enseñar la técnica del levantamiento de pesas. Para mi sorpresa, desde el primer día mi plan fracasó, la halterofilia captó mi atención y durante cinco años disfruté todas mis tardes dedicadas al deporte. Hoy, después de seis años de haberme retirado, mi cuerpo aún tiene impregnada la técnica que me forjó como pesista.

Es por esto que nos surge el interés por estudiar qué es lo que queda implantado en el cuerpo técnicamente después de ser deportista, teniendo en cuenta que aquello que perdura va de acuerdo a las experiencias por las que haya pasado cada cuerpo. Para este caso, la halterofilia es la que nos ayudará a ejemplificar la manera en que, en estos espacios deportivos, la técnica y los discursos sobre el cuerpo se adhieren de forma paulatina a cuerpo y mente, hasta quedar fijos en el cuerpo de quien lo vive.

Cuerpo y mente son los encargados de reflejar y dar sentido a aquellos discursos y técnicas que se imparten en el deporte, y son de alta importancia porque son los elementos que se fusionan para llevar a cabo la disciplina deportiva. El control emocional y físico entra en juego al momento de realizar los movimientos; las sensaciones corporales, los impulsos emocionales y la aprehensión de la técnica se conjugan a tal punto que no se puede disociar cómo se piensan y emplean cada uno de los gestos que configuran el movimiento global del deporte. Wacquant (2006) hace mención 
de la manera en que diversos atributos de la técnica deportiva se conectan para realizar los movimientos correspondientes al boxeo:

"La imbricación mutua de las disposiciones corporales y mentales alcanza tal grado que incluso la voluntad, la moral, la determinación, la concentración y el control de las emociones se transforman en el mismo número de reflejos del cuerpo. En el boxeador hecho y derecho, la parte mental forma parte del físico y viceversa; el cuerpo y la cabeza funcionan en simbiosis total." (pág. 95)

Al igual que en el boxeo, en la halterofilia se observa aquella imbricación de aspectos que contienen aptitudes tanto físicas como mentales que se refuerzan constantemente en el gimnasio, los entrenamientos y las competencias, siendo estos los espacios donde los y las deportistas ejecutan los movimientos que cada deporte requiere, asimilando profundamente la técnica por medio de la repetición. Así, aprender a levantar pesas como boxear, "(...) es modificar sin darse cuenta el esquema corporal, la relación con el propio cuerpo y el uso que de él hacemos habitualmente para interiorizar una serie de disposiciones mentales y físicas inseparables" (Wacquant, 2006, pág. 95)

La relación con el cuerpo, y el uso que a éste se le da, cambia de acuerdo a las técnicas y los discursos que han sido incorporados en él; de acuerdo con el autor Mauss (1979), frente al concepto de técnicas y movimientos corporales, es en la incorporación de las técnicas donde entran a jugar reglas y normas sociales, técnicas y cuidados que moldean los cuerpos variando de acuerdo a los «hábitos» de cada sociedad, de la educación, de los individuos y demás. Al tomar el gimnasio como un espacio que contiene pautas propias sobre cómo debe ser el o la deportista y que construye técnicamente sus cuerpos, se deja en manifiesto el poder de este lugar tanto para consolidar la disciplina como para transformar 
reiteradamente al individuo e invitarlo al autodescubrimiento y a su creación (Wacquant, 2006).

Los pies a la anchura de los hombros. Agarre con gancho. Pecho abierto, hombros hacia atrás. Saque cola. Espalda firme y mirando al frente. Estírese, hacia arriba, jhale duro y salte! ¡Arriba! Acomódese. Cambie el aire. Abra los brazos, abra el pecho y empuje duro. Salte y saque la pierna. ¡Téngalo ahí!

Estas son algunas de las frases que acompañan la técnica del segundo movimiento olímpico de la halterofilia: el envión. Aunque es posible que no se entienda, en su conjunto, fue lo que escuché por tantos años por parte de mis entrenadoras. Tiempo después de retirarme, todo lo que mi cuerpo y mente habían asimilado, lo que habían aprehendido, comenzó a ser objeto de cuestión para mí, de alguna manera y sin lograr desnaturalizarlo, hay un proceso consciente de lo que hago que está fuertemente conectado con lo que fui como pesista. Me di cuenta que mientras se ejecutan algunos movimientos del levantamiento de pesas olímpico no se respira, así que ese cambio de aire que tanto gritaban mis entrenadoras, era realmente un: vuelva a tomar aire.

La conexión que surge con el cuerpo por medio del deporte es difícil de comunicar, así como lo es la transmisión escrita de este conocimiento, sólo se comprende plenamente cuando se sumerge al propio cuerpo a la experiencia de la práctica deportiva, de este modo, la forma en la que los «hábitos» del gimnasio moldean el cuerpo reconfigura la interpretación del mismo.

Lo que los y las entrenadoras dicen en reiteradas ocasiones sobre cómo realizar los movimientos, las posturas adecuadas, la concentración, el manejo de la respiración y los consejos sobre el cuidado del cuerpo, introduce a los y las deportistas en un estado 


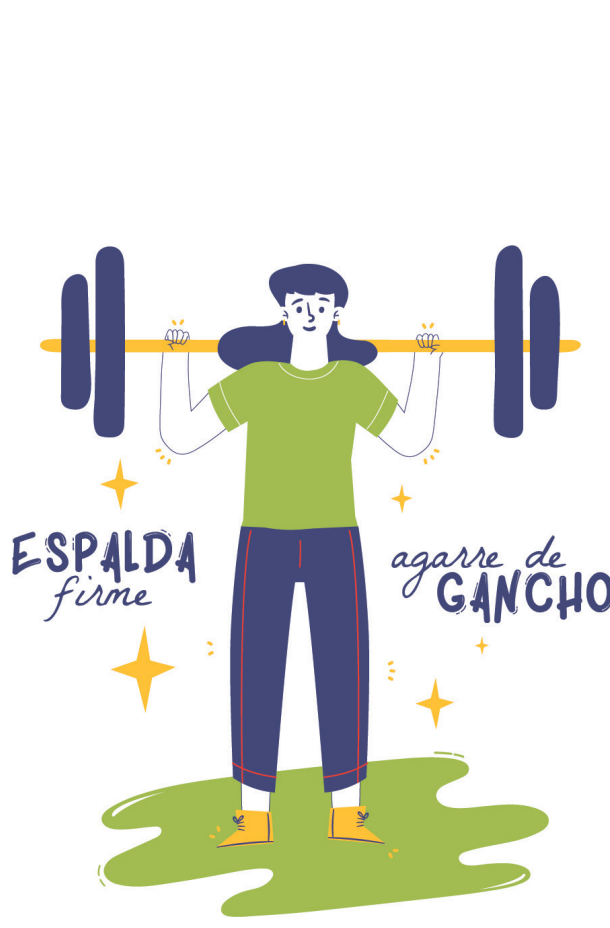

de ocupación permanente por el bienestar y eficacia de sus cuerpos, en el que se generan acciones conscientes e inconscientes que pasan a ser parte de la forma en la que se mueven y comportan cotidianamente, al punto tal de trasladar los discursos, que podrían solo tener sentido en los entrenamientos, a otras esferas de la vida social.

Agarrar con gancho significa tomar con cada mano la barra de acero teniendo el dedo pulgar por dentro de dos de los dedos sobrantes, el índice y el corazón (o medio), esto se hace para sostener con más firmeza la barra y evitar

“... cuando voy parada en un bus agarro con gancho y, además, los pies

los dejo a la anchura de mis hombros para tener equilibrio dentro de él." que se deslice fácilmente mientras se ejecuta el movimiento.

Pero, aunque esto conforma la técnica de la halterofilia, yo lo uso para sostenerme de cualquier objeto con forma similar; por ejemplo, cuando voy parada en un bus agarro con gancho y, además, los pies los dejo a la anchura de mis hombros para tener equilibrio dentro de él. Tengo mi espalda firme cuando voy a levantar cosas pesadas o cuando 
voy en moto para evitar sacudirme con los brincos de la carretera. Y también, miro al frente siempre que necesito concentración.

La construcción de posturas corporales y el manejo de emociones adquieren un sentido particular en el campo deportivo, hay una finalidad, una razón por la que se debe llevar a cabo la halterofilia de una manera específica, pero porqué se replican estas posturas y porqué se busca controlar algunas emociones cuando el deporte ya no hace parte de la vida de un individuo; la adquisición de técnicas y gestos y la aprehensión de discursos sobre cuerpo y mente transgreden los imaginarios sobre las dinámicas que parecen exclusivas de determinados espacios, demostrando que aquello que tiene significado dentro del campo deportivo, también lo puede tener en otras dimensiones sociales del individuo y hacer parte de ellas como expresiones de la experiencia.

Es así como este texto le da relevancia al resultado más evidente de la experiencia del deporte que es la cohesión entre cuerpo y mente; estos dos elementos son de carácter importante pues en el proceso donde se desarrolla esta unión, el o la deportista tiene que haber realizado una serie de movimientos y controles conscientes e inconscientes frente a la técnica y los impulsos emocionales. Conscientes en tanto se tienen que aprender todos los movimientos y posturas necesarias para que se realice de manera adecuada la técnica y también, debe haber una reflexión que permita conocer de antemano cuáles son los impulsos emocionales que invaden al individuo al momento de la acción y que, por ende, se hacen necesarios controlar como la ansiedad o el miedo.

Inconsciente con respecto al tiempo, ya que llega un momento en que aquello en lo que se fija la atención constantemente (técnica y emociones) se encuentra en una sinergia tal que no es necesario pensar y re-pensar en el control que se ejerce sobre ello, pues en 
cuestión de segundos todo se vuelve un elemento amalgamado. En conclusión -y con una suerte de sugerencia-, como investigadores e investigadoras de ciencias sociales, es necesario que haya una participación más activa que identifique, experimente y describa el o los objetos de estudio que nos interesa analizar. Como bien lo menciona Wacquant (2006):

"Nada mejor pues como técnica de observación y análisis que la inmersión iniciática en un cosmos, e incluso la conversión moral y sensual, a condición de que tenga una armadura teórica que permita al sociólogo apropiarse en y por la práctica de los esquemas cognitivos, éticos, estéticos y conativos que emprenden diariamente aquellos que lo habitan." (pág. 16)

De esta manera, es menester dar cuenta de desde la dimensión más experiencial del individuo mostrando la relevancia que esto tiene al momento de desarrollar una investigación que tome la experiencia como eje central de estudio, esta característica se destaca en el presente texto al confirmar su inherencia con el deporte. En este caso, la experiencia de ser deportista y vivir por medio del propio cuerpo la adquisición de nuevas técnicas y movimientos corporales permite dar nuevos significados de lo que es el cuerpo, una herramienta con la que nos comunicamos, interactuamos con el entorno reproduciendo aquellos gestos que dan cuenta de las vivencias de cada sujeto y brindando constantemente una nueva interpretación de la forma en que se entiende, siente y vive el cuerpo. Y es que es precisamente el deporte, una de las actividades que hoy en día se ha tomado el protagonismo para ser parte de la vida de muchas personas presentando elementos de estudio que las ciencias sociales pueden permitirse tomar para ofrecer nuevas perspectivas de investigación. 


\section{Bibliografía}

Mauss, M. (1979). Técnicas y movimientos corporales. En M. Mauss, Sociología y Antropología (págs. 335-356). Madrid: TECNOS.

Wacquant, L. (2006). Entre las cuerdas: cuadernos de un aprendiz de boxeador. Buenos Aires: Siglo XXI. 